\section{Violence and growth in Colombia: A review of the quantitative literature}

\section{Alvaro J. Riascos and Juan F. Vargas}

$\mathrm{C}$ olombia is an exceptional case study for social scientists interested in conflict, crime, and violence in general. It is a country that suffers not only from a civil conflict but also from high levels of crime, forced displacement, kidnapping, and narcotrafficking. Since the 1990s, economists working on Colombia have turned increasing attention to the analysis of the causes and costs of crime and conflict and the academic output is now abundant. Yet this literature is virtually unknown to the international academic community. ${ }^{1}$ The aim of this article thus is to provide a brief review of the evolution and state of art of the research on the relationship between violence and economic growth in Colombia. We hope to demonstrate that Colombia is an interesting case well worth studying and contribute to the diffusion of this literature among academics and policymakers working in the field of violence.

The review follows three guidelines. First, we focus on quantitative studies on the effect of violence on economic growth. ${ }^{2}$ Second, we do not distinguish among works using conflict or crime variables, nor we differentiate between forms of crime or ask about their origins. While the majority of the papers we refer to focus on crime, some of them also use data on the internal conflict. Although they can be related in specific contexts, crime and conflict are different phenomena and their interrelation has not yet been studied sufficiently. ${ }^{3}$

Throughout, we stick to crime and conflict concepts as used in the specific papers we review. Otherwise, we will use the word violence generically, although we recognize this is problematic. ${ }^{4}$ For example, the concept of crime is itself quite broad. It is variously associated with the homicide rate, manslaughter, street crime, crime against property, drug trafficking, kidnaping, or a mixture of some or all of these. Although we believe that a clear distinction of the different types of crime and their impact on economic growth should be at the top of any research agenda, in this review, once more, we use the term violence in a generic way.

Our third guideline concerns the emphasis we place on the rate of growth of the economy as the outcome variable of interest. That is, we abstract from the long-term relationship between violence and the economy and focus on the short-term , leaving aside studies that have had as their variable of interest the level of output. ${ }^{5}$ As illustrated by Figure 1, these are indeed very different concepts and associated research questions. The figure shows the evolution of the level of real per capita GDP (left axis) and its rate of growth (right axis) for the period 1950-2005, measured in purchasing power parity terms. ${ }^{6}$ After a short episode of negative growth in 1958 the country grew steadily (and with low volatility) until the mid-1970s. The rate of

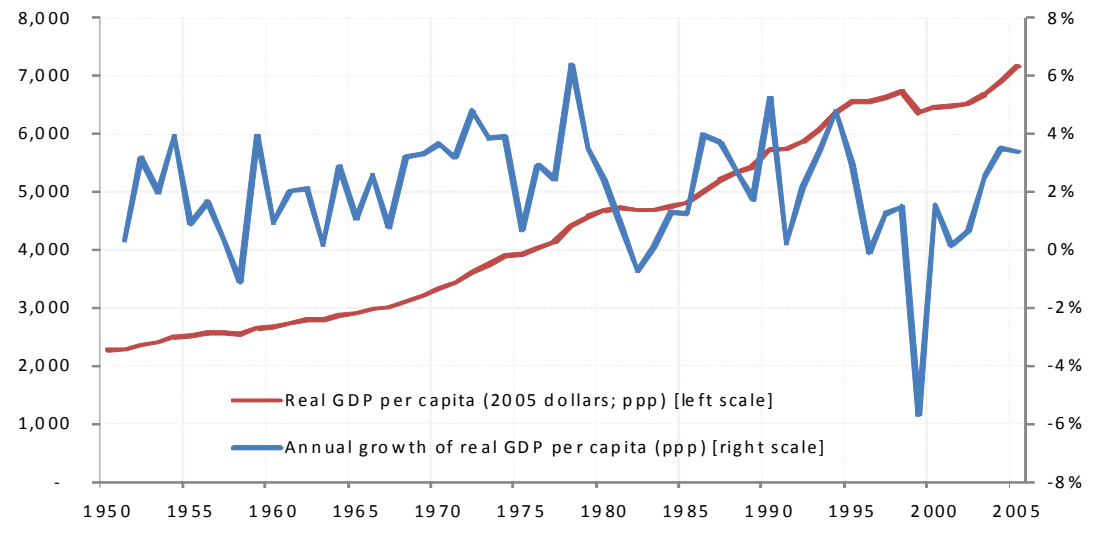

Figure 1: Real per capita GDP and GDP growth, Colombia, 1950-2005 (in purchasing power parity dollars, 2005).

Source: DANE (various), GRECO (2002), and Florez (2000). See text.

growth was again negative in 1982 but, in contrast to the rest of the Latin America region then hit by a debt crisis, Colombia rapidly resumed its growth path, albeit with a perceptible increase in volatility. In 1999, an unprecedented domestic crisis made Colombia's per capita growth rate reach its all-time low at (nearly) minus six percent. After a large upward bounce in 2000, the growth rate recovered.

The changes in the growth rate of the economy have left their trace in the real per capita GDP level of course, but Figure 1 also shows that the latter has increased steadily over the whole 1950 to 2005 period. In fact, average output per person has more than tripled.

This review is not meant to be exhaustive. We have made an effort to survey the most influential studies given the topic limitations that we have imposed on ourselves. Over the last two decades, the empirical literature on violence and economic growth in Colombia has evolved from simple comparisons and cost accounting exercises to more sophisticated techniques and the use of specific theoretical frameworks. This coincides with the recent trend in the international literature, which increasingly is making use of modern techniques to better understand the dynamics of violence, crime, and conflict. ${ }^{7}$ Our contribution is to document the evolution and current state of research pursued by economists and other social scientists interested in Colombia as a case study of a violent country.

Violence and economic growth in Colombia

Economists in Colombia became interested in studying violence using quantitative approaches some 15 years ago. The first few papers were conceived as a reaction to 
a 1988 study by a multidisciplinary group of social scientists that related Colombia's growing record of violence to variables associated with economic deprivation. ${ }^{8}$ A few years later, in 1995, three independent quantitative studies by Gaitán, Rubio, and by Montenegro and Posada questioned this conclusion, which by that time had already become part of the local "conventional wisdom." In contrast to the qualitative approach of the 1988 interdisciplinary study, the 1995 articles were at the time novel in their quantitative approach and should be identified as pioneers in the empirical analysis of the relationship between violence and the economy in Colombia.

While Gaitán (1995) focuses on the determinants of violence incidence, Rubio (1995) and Montenegro and Posada (1995) tackle the problem in terms of its consequences on economic growth. We therefore exclude the former from the survey.

Focusing on the 1980s and early 1990s, Rubio (1995) explores the correlation between the aggregate homicide rate (killings per 100,000 people) and GDP growth. The author concludes that the persistently high homicide rate during that period prevented the economy from growing two additional percentage points per year. In contrast, Montenegro and Posada (1995) [hereafter MP] find a positive relationship between the homicide rate and GDP growth at the regional level during the late 1970s and the 1980s. They argue that the high level of violence during that period was the result of the rapid economic growth of some regions that did not have the required institutional strength (e.g., protection of property rights) to transform this growth into a virtuous circle of development without crime. In turn, the fast output growth created wealth easy to predate and disrupt. Rubio (1995) shows that the results of MP are not robust to changing the estimation period and provides evidence in turn consistent with the idea that more violent periods unambiguously coincided with lower growth rates.

From a methodological point of view, MP's findings come from estimating an econometric model in which the dependent variable is the regional growth rate and the main explanatory variable is the homicide rate. The latter is included both in levels and as a squared term to explore potential nonlinearities. Indeed, the authors find a nonmonotonic (inverted-U) relationship. Their interpretation is that when violence reaches some critical threshold, the positive correlation between crime and growth reverses and crime starts hampering economic growth. In short, the story that MP put forward is idiosyncratic. At lower levels of violence causality runs from economic growth to violence: High economic growth causes violence to increase. But when violence is high enough causality runs in the other direction: Higher violence causes economic growth to slow down. While such story illustrates the classic endogeneity problem of reverse causality, MP make no attempt to deal with the identification issue.

In Rubio (1995), the analysis of the relationship between growth and violence goes beyond the observation of simple correlations. The author investigates for the 1980s the relationship between the declining levels of Colombia's total factor productivity (TFP) and violence levels, which increased during the same period. By running an OLS regression of the time series of these variables (controlling for the then high and volatile inflation rate), Rubio finds that the increase in the homicide rate during the 1980s was directly responsible for an aggregate growth loss of about two percentage points per year.

Rubio explores a potential indirect channel as well and OLS-regresses aggregate investment on the homicide rate. Controlling for more traditional determinants of investment decisions, the author finds that the increasing homicide rates hampered private investment, costing the country an additional 0.7 percent of GDP growth per year.

The overall conclusion of Rubio (1995) is that, in the counterfactual situation in which crime had not increased so much in the 1980s, annual economic growth in Colombia would have been over 2.5 percentage points higher. It is worth noting that this figure is rather similar to the one provided by Collier (1999). Collier looks at the relationship between civil conflict and economic growth in the second half of the twentieth century for a sample of countries and estimates that the incidence of war is associated with a growth rate reduction of 2.2 percentage points. To appreciate the magnitude of this effect, note that an economy growing at a real rate of 2.5 percent annually will double its size in just 28 years.

Rubio's paper and methodology inspired researchers. One is Parra (1998) who delves into the burden violence imposes on investment. Another is Cardenas (2007), whose motivation is actually the same as that of Rubio: the decline in TFP experienced during the 1980s in Colombia. In addition to violence, Cardenas (2007) also explores the role of inequality on the TFP slow-down.

Parra (1998) regresses the aggregate investment rate in the second half of the twentieth century on a number of variables, including proxies of the cost of capital, a measure of economic activity, a proxy of aggregate human capital, and the (lagged) growth of the homicide rate as a proxy of the overall violence of the country. ${ }^{9}$ Parra finds that if violence levels were equal to the Latin American average prevailing during the 1990s (which implies a reduction of 75 percent of the actual Colombian rates), the investment rate would have been 50 percent higher, boosting economic growth. Put another way, given the period-average share of investment in GDP, a reduction of 10 percent in the homicide rate would have translated into additional 1.2 percent in the annual rate of economic growth.

Cardenas' (2007) econometric analysis is motivated by a comparative description of Colombia against a large sample of countries in terms of size, macroeconomic 
performance, trade, indebtedness, geography, health, income, wealth inequality, population fragmentation, political institutions, and the incidence of violence. Colombia shows up as an "average” country in all but two measures: economic inequality and violence. Colombia's income-Gini (0.51) is higher than the world average; and the land-Gini (0.86) is one of the highest of the world. Moreover, Colombia is a world-outlier in terms of violence, ranking first among 80 countries in 1995 in terms of the homicide rate, with 80 killings per 100,000 inhabitants.

Such comparisons motivate Cardenas' hypothesis regarding the role of inequality and violence as possible obstacles to improving Colombia's economic performance. The author runs an auto-regressive model of the growth of GDP for the period 1950 to 2000 and incorporates year-specific binary variables to uncover potential structural changes in the country's economic growth. He finds one such shift taking place in 1979: Colombia's economic growth fell from an average of five percent in the period 1950-79 to an average of three percent in 1980-2000.

Using a neoclassical constant returns to scale production function with human capital, Cardenas performs a growth accounting exercise to explore the factorial sources of this structural change. The estimated Solow residual suggests what the author calls an implosion of Colombia's TFP: During the period 1950-1979, the TFP growth rate was on average 1.01 percent. In contrast, between 1980 and 2000 it was -0.95 percent.

Cardenas' hypothesis is that the productivity slowdown is explained by both the huge increase in crime and the growing inequality: On the one hand, production of cocaine rose from an annual average of less than 100 tons before 1980 to more than 500 tons in 1999, and illicit crop planting increased form 20,000 to 140,000 hectares in the same period. The homicide rate increased monotonically from 23 killings per 100,000 inhabitants in the 1970s to 41 in the 1980s and 62 in the 1990s. Kidnapping increased from an annual average of 44 in the 1980 s to 3,706 in 2000. On the other hand, starting in 1980 the income-Gini increased steadily from 0.46 in 1982 to 0.53 in 2000, offsetting a downward trend that started at the beginning of the 1960s.

Cardenas also explores potential transmission mechanisms. He argues that crime and violence destroy the "social infrastructure" (a concept motivated by Hall and Jones, 1999) and hence damage productivity by encouraging predatory behaviors that divert capital and labor to unproductive activities. To test these arguments the author runs an OLS regression of the previously estimated Solow residual on the homicide rate and the Gini coefficient, finding evidence of a negative correlation of both factors with the dependent variable.

Cardenas (2007) was an influential paper among younger Colombian economists who started studying the relationship between violence and economic growth in Colombia in the early 2000s. One example is Vargas (2003) who distinguishes crime from conflict-specific events and takes advantage of a unique data set on the latter to focus, for the first time, on the effects of the Colombian internal conflict on the country's economic performance. Previous studies had used the homicide rate as the best proxy of crime but a closer inspection suggest that it is poorly correlated with the dynamics of the conflict itself.. ${ }^{10}$ Vargas proposes a systematic way of thinking of the channels through which the conflict may affect the rate of economic growth. He argues that in the context of a simple production function, conflict intensity can affect the growth rate of output both directly, by shifting productivity downward, and indirectly, by hindering the accumulation of factors of production (i.e., both physical and human capital). Thus, the author develops a neoclassical growth model in which both total factor productivity and the accumulation of physical and human capital are affected by the intensity of conflict.

To quantify the impact of conflict on growth, Vargas estimates by 3SLS a system of equations using quarterly data from 1988 to 2001. In the first equation, GDP growth is a function of physical and human capital as well as of the intensity of conflict. ${ }^{11}$ The second and third equations capture, respectively, by using autoregressive processes, the dynamics of physical and human capital. Also, measures of the intensity of the conflict are added in both equations. This strategy allows Vargas to capture the direct impact of conflict on economic growth (through the coefficient of the conflict-proxy in the first equation) as well as the indirect impact. The latter is the effect of conflict on the accumulation of factors of production times the contribution of each factor to the growth rate of output, as captured by the first equation.

Vargas estimates that the increase in the intensity of the Colombian conflict since the late1980s slowed the per capita economic growth rate by 0.3 percentage points on average during the 1990s. In particular, the large upsurge of conflict activity starting in the late 1990s was responsible for about a one percentage point loss in the per capita growth rate. Most of this impact (90 percent) is a direct impact via TPF growth, and the rest is indirect via the accumulation of physical capital.

While it appeals to a simple but formal theoretical framework to organize the empirical strategy, Vargas study has a major shortcoming that is common to all the papers reviewed so far: It does not address the problems of simultaneity and omitted variables bias. In this respect, the paper by Querubin (2003) stands out. The author exploits the panel structure of the available data (department-level variation over time), which contrasts with the dominant time-series approach. ${ }^{12}$ The author takes into account the potential for omitted variables, especially given the lack of regional data on important economic variables, as well as the difficulty in finding reasonable instruments to solve for the endogeneity between violence and growth. Because both the rate of growth and the growth of violence change over time as opposed to most of the other determinants of regional growth, Querubin argues that taking the first difference of the growth equation eliminates all the departmental-specific fixed effects.

While this methodology solves the omitted variables problem for time-invariant controls, the reverse-causality issue is still at play and hence conclusions in this case also have to be taken with caution. ${ }^{13}$ Controlling for other time-varying growth rate 
variables (transfers from the central government and income from illegal drugs), Querubin estimates the panel by GLS. His measure of violence is a three-dimensional vector including the homicide rate, the number of kidnapping, and the number of actions of illegal armed groups. The three measures of violence turn out to be statistically significant at the one percent level and have the expected sign.

According to the results, an increase of 10 percentage points in the rate of growth of the homicide rate implies an annual reduction of 0.37 percentage points in the GDP growth rate. Similarly, the effect is 0.13 if the increase is on the rate of growth of the kidnapping rate, and 0.07 in the case of illegal attacks.

Querubin (2003) is the last paper in our survey that looks at the direct relationship between violence and economic growth. We speculate that, by acknowledging the existence of potential endogeneity between the incidence of violence and economic performance, Querubin paved the road for the more recent generation of empirical studies on the effects of violence in Colombia. Indeed, these more recent papers have focused on the impact of violence on specific mechanisms that in turn may affect economic growth, while at the same time undertaking explicit efforts in making causal statements. These include the accumulation of human capital, the micro decisions of the productive firms, early childhood development, and sovereign risk. ${ }^{14}$ We do not review these contributions here because while the channels are made explicit, the ultimate effect on economic growth remains speculative. However, these are certainly topics and papers that deserve a review of their own.

\section{Discussion}

Since the mid 1990s the literature on conflict and crime in Colombia has expanded rapidly, being now one of the main research agendas of local social scientists. One of the topics of this agenda is the relationship of violence, broadly understood, to economic performance. While this particular topic was studied in the late 1990s and early 2000s, little research has been done since then and the currently predominant research questions focus on different topics: The determinants of violence incidence and its duration, the determinants and the spatial dynamics of illicit crops, and the effect of violence on specific channels that are thought to affect economic performance. ${ }^{15}$ But the general point is that the last two decades have witnessed a boom in the economic analysis of violence and conflict in Colombia.

We believe that the final word about the effect of violence on economic performance is far from been said. Besides the fact, already mentioned, that all the papers surveyed lack a convincing identification strategy, the bulk of the literature has focused on the short-term relationship with economic performance, overlooking how violence shapes long-term economic performance. Indeed, this is the variable more closely associated with what likely is to be the main motivational driver of all these type of studies: sustainable economic development.

Future research on the topic may result in large potential payoffs on at least three fronts: (1) thinking of clever identification strategies that allow causal inference statements on the relationship between violence and economic performance; (2) linking the channels identified as conflict-affected, and that are likely to have an impact on economic performance, with the actual ultimate outcome; and (3) looking at how violence affects long-term development and, related to the second front, through what mechanisms this happens. In addition, we also expect to see the introduction of more structural and game theoretic modeling strategies with an eye to empirical application.

This is an ambitious agenda, but we anticipate that it will not remain unfulfilled. In fact the pool of economists (both local and foreign) interested in the topic is growing steadily. We foresee that studies in the areas suggested will soon proliferate: As a case study that combines a long-lasting history of violence with the availability of reliable micro-data, Colombia can become a source of academic output that can guide research on conflict, crime, and civil war in its shift from cross-country correlations to micro-level-based analyses. Happily, this process has already started.

Notes

Alvaro Riascos is Professor of Economics at the Universidad de los Andes, Bogotá. Colombia. He may be reached at<ariascos@uniandes.edu.co>. Juan Vargas, the corresponding author, is Professor of Economics at Universidad del Rosario, Bogotá. Colombia. He may be reached at <juan.vargas@urosario.edu.co>. This is a substantially revised version of an essay originally published on $<$ www.webpondo.org>. We thank Jurgen Brauer for helpful comments and Andrés Castañeda for useful research assistance.

1. One exception is a forthcoming special issue on Colombia in Defence and Peace Economics. However, none of the papers included in that issue study the relationship between violence and economic growth directly.

2. A separate question that has also received large attention in the last few years is that of the economic determinants of violence in Colombia. Relevant studies in this field include Comisión de Estudios sobre la Violencia (1988); Gaitan (1995 and 2001); Sarmiento (1999); Sánchez and Nuñez (2001) and more recently Rodriguez and Daza (forthcoming). Without denying the importance of this question, for the sake of space we overlook it in the present survey. For a short review of the determinants of violence in Colombia see Martinez (2001).

3. An exception is Sánchez, Díaz, and Formisano (2003) who use spatial econometrics to explore the link between crime and conflict in Colombian regions. 
4. The World Health Organization (2002) differentiates among self-harm (e.g., suicide), interpersonal violence, and collective violence. While only the latter has systematically been studied by social scientists interested in civil war, the study of interpersonal violence is often limited to crime economists. Our review of contributions in both fields responds to our personal belief that the fields have much to learn from each other.

5. Also, we do not review studies that look at the effect of violence on intermediate outcomes that may, in turn, have an impact on economic growth. Indeed, the research on the transmissions mechanisms linking violence and growth in Colombia is scarce. One exception is Dinar and Keck (1997) who argue that conflict adversely affects private irrigation investments in rural Colombia and, through that channel, harms economic growth.

6. GDP data comes from a compact disk accompanying GRECO (2002). (GRECO is the acronym of an economic growth research group at Colombia's central bank). For 2001 onward, the series was updated by DANE, Colombia's statistics office. For per capita computations, population is based on census data; Florez (2000).

7. See Blattman and Miguel (2010) for a recent comprehensive review.

8. Comisión de Estudios sobre la Violencia (1988).

9. The paper lacks a convincing justification for using the growth rate rather than the level of the homicide rate in a regression of the burden on private investment.

10. Best proxy: e.g, Rubio (1994). Poorly correlated: Restrepo, et al. (2004).

11. He uses various measures that go from clashes and attacks to casualty rates.

12. Rubio (1995), Parra (1998), Cardenas (2007), Vargas (2003); MP’s approach is a regional-pooled OLS regression.

13. While the author refers to his method as a difference-in-difference (DD) approach, this is not so, at least not in the sense that DD is traditionally understood in microeconometrics, i.e., one in which an indicator of the treatment group is interacted with one of the post-treatment period, which generates a natural counterfactual difference to compare outcome-gains in the treatment group with. Rather, Querubin's regression is one of acceleration rates (second differences) of the variables of interest.
14. Human capital: Rodriguez and Sánchez (forthcoming). Productive firms: Camacho and Rodriguez (2011). Early childhood development: Camacho (2008). Sovereign risk: Castañeda and Vargas (forthcoming).

15. Incidence: Nuñez and Sánchez (2001) and Dube and Vargas (2008). Duration: Vargas (forthcoming). Determinants and spatial dynamics: Díaz and Sánchez (2004). Specific channels: see endnote 14.

\section{References}

Blattman, C. and E. Miguel. 2010. “Civil War.” Journal of Economic Literature. Vol. 48, No. 1, pp. 3-57.

Camacho, A. 2008. "Stress and Birth Weight: Evidence from Terrorist Attacks." American Economic Review (Papers and Proceedings). Vol. 98, No. 2, pp. 511-515.

Camacho, A. and C. Rodriguez 2011. "Firm Exit and Armed Conflict in Colombia.” Mimeo. Bogotá: Universidad de los Andes.

Cárdenas, M. 2007. "Economic Growth in Colombia: A Reversal of 'Fortune'?” Ensayos Sobre Política Económica. Vol. 25, No. 53, pp. 220-259.

Castañeda, A. and J.F. Vargas. Forthcoming. "Sovereign Risk and Armed Conflict: An Event-Study for Colombia.” Defence and Peace Economics.

Collier, P. 1999. "On the Economic Consequences of Civil War." Oxford Economic Papers. Vol. 51, No. 1, pp. 168-183.

Comisión de Estudios sobre la Violencia. 1988. Colombia: Violencia y Democracia. Conciencias. Bogotá: Universidad Nacional,

DANE. Colombia National Statistics Office. (Recent GDP data can be downloaded from its website: www.dane.gov.co.)

Diaz, A.M. and F. Sánchez. 2004. "Geografía de los Cultivos Ilícitos y Conflicto Armado en Colombia.” Documento CEDE 2004-18. Bogotá: Universidad de los Andes-CEDE.

Dinar, A. and Keck, A. 1997. "Private Irrigation Investment in Colombia: Effects of Violence, Macroeconomic Policy, and Environmental Conditions.” Agricultural Economics. Vol. 16, No. 1, pp. 1-15.

Dube, O. and J.F. Vargas. 2008. “Commodity Price Shocks and Armed Conflict: Evidence from Colombia.” Mimeo. Harvard University.

Florez, C.E. 2000. Las transformaciones sociodemográficas en Colombia. Bogotá: Banco de la Republica and Tercer Mundo Editores.

Gaitán, F. 1995. “Una Indagación sobre las Causas de la Violencia en Colombia,” in M. Deas and F. Gaitán, Dos Ensayos Especulativos sobre la Violencia en Colombia. Bogotá: Tercer Mundo Editores.

GRECO. 2002. El crecimiento económico colombiano en el siglo XX. Bogotá: Banco de la Republica and Fondo de Cultura Economica. 
(c) www.epsjournal.org.uk - Vol. 6, No. 2 (2011)

Hall, R. and C. Jones. 1999. "Why do Some Countries Produce so Much More Output per Worker than Others?” The Quarterly Journal of Economics. Vol. 114, No. 1, pp. 83-116.

Martinez, A. 2001. "Análisis de la Violencia en Colombia. Una Nota sobre la Literatura.” Cuadernos de economía. Vol. 20, No. 34, pp. 157-187.

Montenegro, A. and C.E. Posada. 1995. “Criminalidad en Colombia.” Coyuntura Económica. Vol. 25, No. 1, pp. 81-100.

Parra, C.E. 1998. "Determinantes de la Inversión en Colombia: Evidencia sobre el Capital Humano y la Violencia.” Archivos de Economía Vol. 84. Bogotá: Departamento Nacional de Planeación, Colombia.

Querubín, P. 2003. “Crecimiento Departamental y Violencia Criminal en Colombia.” Documento CEDE 2003-12. Bogotá: Universidad de los Andes-CEDE.

Restrepo, J.A., M. Spagat, and J F Vargas. 2004. “The Dynamics of the Colombian Civil Conflict: A New Data Set.” Homo Oeconomicus. Vol. 21, No. 2, pp. 396-428.

Rodriguez, C. and F. Sánchez. Forthcoming. "Armed Conflict Exposure, Human Capital Investments, and Child Labor: Evidence from Colombia.” Defence and Peace Economics.

Rodriguez, M. and N. Daza. Forthcoming. "Determinants of Civil Conflict in Colombia: How Robust are they?" Defence and Peace Economics.

Rubio, M. (1995). “Crimen y Crecimiento en Colombia.” Coyuntura Económica. Vol. 25, No. 1, pp. 101-128.

Sánchez, F. and J. Núñez. 2001. "Determinantes del Crimen Violento en un País Altamente Violento,” pp. 285-326 in A. Martinez, ed., Economía, Crimen y Conflicto. Bogotá: Universidad Nacional.

Sánchez, F., A.M. Díaz, and M. Formisano. 2003. “Conflicto, Violencia y Actividad Criminal en Colombia: Un Análisis Espacial.” Documento CEDE 2003-5. Bogotá: Universidad de los Andes-CEDE.

Sarmiento, A. 1999. "Violencia y Equidad.” Planeación y Desarrollo. Vol. 30, No. 3, pp. 47-80.

Vargas, J F. 2003. “Conflicto Interno y Crecimiento Económico en Colombia.” M.A. thesis. Bogotá: Universidad de los Andes.

Vargas, J.F. Forthcoming. “The Persistent Colombian Conflict: Subnational Analysis of the Duration of Violence.” Defence and Peace Economics.

World Health Organization. 2002. World Report on Violence and Health. Geneva: WHO. 